\title{
Ecological status and diversity indices of Panchaule (Dactylorhiza hatagirea) and its associates in Lete village of Mustang district, Nepal
}

\begin{abstract}
C. B. Khadka ${ }^{1}$, A. L. Hammet ${ }^{2}$, A. Singh ${ }^{3}$, M. K. Balla ${ }^{3}$ and Y. P. Timilsina ${ }^{3}$
This paper focuses on the ecological status and diversity indices: Simson's Index (C), Simson's Index of Dominance (D) and Shannon-Weaver Index (H) of Dactylorhiza hatagirea and its associates- Rheum australe and Rumex nepalensis in Lete village of Mustang District within the Annapurna Conservation Area. The study was conducted during the monsoon season (June/July) of 2013 in the Lete VDC of Mustang District. The study site possessed an area of 4.5 ha. Altogether, 100 circular plots, each with $25 \mathrm{~m}^{2}$ area, were laid out purposively within the study area; the sampling intensity being $5.55 \%$. The relative frequency, the relative density, the abundance, the relative coverage and the Important Value Index of the species were found to be $61.11,53.91$, $1,061.54,72.2$ and 187.24 respectively. Similarly, the Simson's Index (C), the Simson's Index of Dominance (D) and the Shannon-Weaver Index of the species were found to be $0.41,0.59$ and 3.27 respectively, indicating relatively even and relatively diverse community. The study showed relatively higher values of all the parameters of $D$. hatagirea as compared to its associates indicating good ecological value. However, threats remain due to the illegal harvesting of this valuable orchid and overgrazing in the study site.
\end{abstract}

Key words: Biodiversity, community, conservation, medicinal plants

$\mathrm{N}$ epal constitutes a unique and enormous diversity of flora and fauna within a relatively small geographical area due to variations in topography, altitude and climate. In spite of being a small country, it possesses around 7,000 species of vascular plants with 2,000 species of medicinal plants (Shrestha and Shrestha, 1999). Baral and Kurmi (2006) have compiled and described 1,792 medicinal plants. According to Bhattarai and Ghimire (2006), 49\% of the traded medicinal plants are herbs, $29 \%$ trees, $14 \%$ shrubs and $8 \%$ climbers. So, Nepal is a veritable treasure trove of medicinal plants (Phoboo et al., 2008).

During the last 10 years, a great interest has been given for the promotion of Non-Timber Forest Products (NTFPs) throughout the world. Huge sums have been invested in exploring the potential of NTFPs (Wollenberg, 1999). Nepal is also not far from this condition. The Master Plan for Forestry Sector (1988), Forest Policy (2015) and the Thirteenth Plan (2013-2016) had emphasized the development and commercialisation of Medicinal and Aromatic Plants (MAPs) as a priority programme for poverty alleviation. This shows the commitment of the government for conservation and management of medicinal plants in the nation. Rare and high-priced medicinal herbs are on the top priority for their domestication, research and cultivation, processing and marketing.

MAPs of high altitudes are invaluable resources not only to the local communities and the nation, but also to the global community at large. They have high ecological as well as economical values, and so the poor rural communities are highly dependent on them for their livelihoods.

Out of many MAPs, Dactylorhiza hatagirea (D. Don) Soo under the family of Orchidaceae commonly known as "Panchaunle" in Nepali has been listed in Appendix II by the Convention on International Trade in Endangered Species

\footnotetext{
${ }^{1}$ Chitwan National Park, Chitwan, Nepal. Email : chhatra10@gmail.com

2 Virginia Polytechnic Institute, Virginia, USA

Institute of Forestry, Pokhara, Nepal
} 
of Wild Fauna and Flora (CITES), vulnerable species listed by the Conservation Assessment and Management Plan (CAMP) and threatened species by the International Union for Conservation of Nature (IUCN) (Samant et al., 2001). This Himalayan endemic medicinal orchid is found in Hindu Kush Himalaya range (IUCN, 2004). It occurs in the sub-alpine and the alpine zones between 2,800 $\mathrm{m}-4,200 \mathrm{~m}$ altitude above the mean sea level (IUCN, 2004). Other than Nepal Himalayas, it occurs in the same altitudinal ranges of India, Pakistan, Bhutan and China too.

It is a terrestrial-ground-dwelling perennial herb. Its stem is erect, hollow and obtuse, and bears palmately lobed and lanceolate leaves with sheathing leaf-base. The cylindrical and terminal spike bears rosy purple flowers with green bracts (Fig. 1). Flowers are 1.7-1.9 cm long with curved spur. The inflorescence consists of a compact raceme with 25 to 50 flowers developed from axillary buds. The dark purple spotted lip of the flower is rounded and lobed (1 to 5). The plants store a large amount of water in their tuberous roots to survive in arid conditions (Chaurasia et al., 2007).

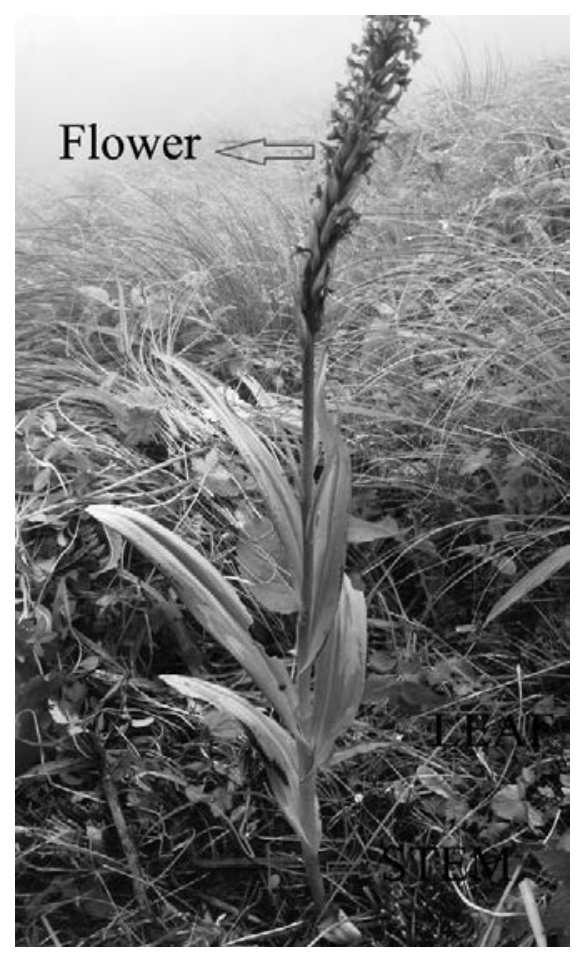

Fig. 1: D. hatagirea plant

The Government of Nepal has prioritized 30 important medicinal plants for the purpose of their research and management. Among those, 12 plants have been selected for agro-technology. $D$. hatagirea is one of them (DPR, 2006). According to Forest Act 1993 and Forest Regulation 1995, the Government of Nepal has banned the collection, trade and processing of the rhizome of D. hatagirea.

As with many other terrestrial orchids, the populations of $D$. hatagirea have decreased due to their habitat loss. Another threat to $D$. hatagirea is the collection of their tubers to make salep (paste made to cure wounds), used as food and medicine. This is a particularly important threat in the Himalayas (Srivastava and Mainera, 1994), where $D$. hatagirea is judged critically endangered (CAMP, 1998) due to their overcollection. Thus, several species of $D$. hatagirea are declining, and some are already protected at a national scale, e.g., in Belgium, Luxembourg, Nepal, and the United Kingdom (Pillon et al., 2005).

The concept of diversity, including biodiversity itself as well as the narrower concept of species diversity, is a human reflection without any unique mathematical meaning. The simplest measure of species diversity is species richness, but a good case can be made for giving some weight to evenness as well. Diversity indices are mathematical functions that combine richness and evenness in a single measure, although usually not explicitly. Although there are many others, the most commonly used diversity indices in ecology are Shannon Diversity, Simpson Diversity, and Fisher's Alpha. Both Shannon and Simpson diversities increase as richness increases, for a given pattern of evenness, and increase as evenness increases, for a given richness, but they do not always rank communities in the same order. Simpson Diversity is less sensitive to richness and more sensitive to evenness as compared to Shannon Diversity, which, in turn, is more sensitive to evenness than is a simple count of species richness (S) (Colwell, 2009).

There are very few studies conducted especially regarding ecological status and diversity of $D$. hatagirea. There is a lack of management and conservation plan from the government side. Similarly, lack of awareness of importance regarding $D$. hatagirea among the rural villagers is leading towards the extinction of this valuable species. Although it is a banned species, its unwise harvesting, unscientific use and illegal trading are in practice which in turn is resulting in the 
reduction of net income of the primary collectors and the government revenue. The objectives of the research study were:

i) to document the ecological status of $D$. hatagirea and its associates in the study site, and

ii) to calculate diversity indices of $D$. hatagirea and its associates in the study site.

\section{Materials and methods}

\section{Study area}

The study was conducted in Paplekharka, a grass land situated in the Lete Village Development Committee (VDC) of Mustang District (Fig. 2) which lies in the Annapurna Conservation Area (ACA).

Mustang District lies between $28^{\circ} 24^{\prime} \mathrm{N}$ to $29^{\circ} 20^{\prime}$ $\mathrm{N}$ latitude and $83^{\circ} 30^{\prime} \mathrm{E}$ to $84^{\circ} 15^{\prime} \mathrm{E}$ longitude. The altitudinal range varies from $1,372 \mathrm{~m}$ to 8,167 $\mathrm{m}$ above the mean sea level representing subtropical, temperate and alpine types of climate (Ranapal, 2009). The Lete VDC lies within the Jomsom Unit Conservation Office (UCO) of the Lower Mustang which is a transition between the Trans-Himalaya and the Inner Himalaya. The VDC receives $1,545 \mathrm{~mm}$ annum rainfall (ACAP, 2009). It consists of deep gorges made by the Kaligandaki River.

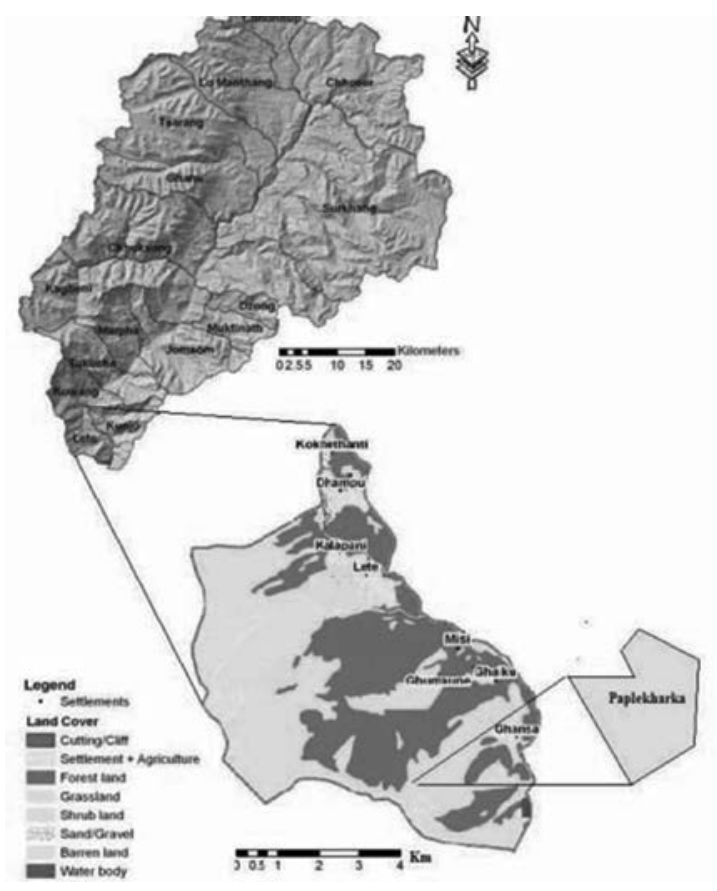

Fig. 2: Landuse map of the study site

\section{Sampling Design}

The inventory was carried out in 4.5 ha during the monsoon season (June/July) in 2013. A $21 \mathrm{~m} \times 21$ $\mathrm{m}$ grid (plot to plot distance) was laid on the map and, altogether, 100 plots were established using the Arc Map Geographical Information System (GIS) Software of version 10; the sampling intensity being $5.55 \%$ (the greater intensity was due to the small area of the study site). Among the 100 plots, the plants of $D$. hatagirea were found in 34 plots only. The sample plots were chosen purposively so that the plots where the plants of $D$. hatagirea and its associates were found would not be left during the field inventory as the topography in some plots was either rocky or stiff or with dense forest cover or barren (Fig. 3).

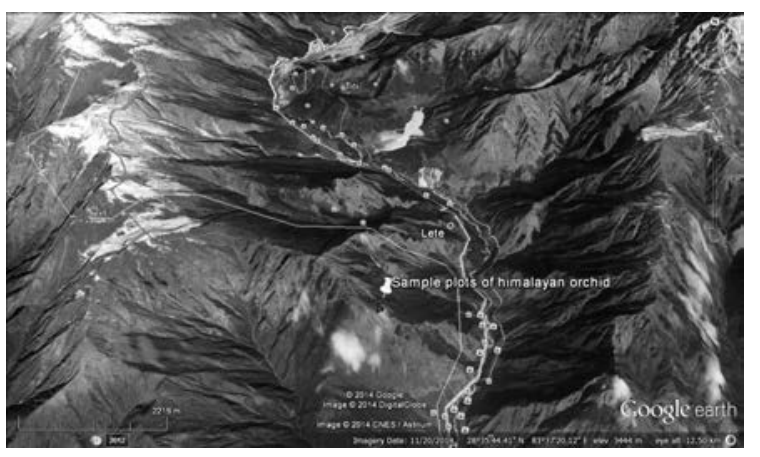

Fig. 3: Google Image (20-11-2014) of the Lete VDC showing the location of the sample plots for the inventory of $D$. hatagirea

All the plants of $D$. hatagirea found in 26 plots were measured. The number of plots in which D. hatagirea was absent was 15 (in which other herbs were also present) excluding the plots with barren, forest, rocky and stiff topography. Similarly, out of the total 100 plots, 20 plots included barren area, 16 plots forest area and 23 plots rocky and stiff area in which inventory was not possible.

\section{Study methods}

\section{Primary data collection}

The primary data was collected through reconnaissance survey and herb inventory. First of all, a reconnaissance survey was carried out for general field observation, rapport building with the local people and the ACAP personnel about the trail of the location where $D$. hatagirea was found. Besides, a sketch map was also prepared for carrying out the field inventory smoothly. 
Generally, $1 \mathrm{~m} \times 1 \mathrm{~m}$ sample plots are used for inventory of herbs. However, as D. hatagirea is a low abundant herb, circular sample plots of $25 \mathrm{~m}^{2}$ were established as recommended by Ravindranath and Premnath (1997). All the plants of $D$. hatagirea and its associate species were counted and their mean height, mean collar diameter ( $5 \mathrm{~cm}$ above the ground) and mean age were measured within the sample plots. The mean age of $D$. hatagirea was calculated by summing up all the ages of $D$. hatagirea plants and dividing by the number of plots where $D$. hatagirea occurred. Similar process was repeated to calculate the mean height and the mean collar diameter of the species. A Global Positioning System (GPS) set was used to locate the plots, and a 20-meter Reel Tape was used to measure the radius of the plot. Similarly, Vernier Calliper was used to find out the collar diameter of the herb whereas a 5feet Steel Tape was used to detect the height of the herb. An Inventory Sheet was developed to record the details for calculating the ecological status and the diversity indices of the species.

\section{Secondary data collection}

The secondary data were obtained with the help of the annual reports, newsletters, bulletins, journals, dissertations, publications, maps and so on available in the ACAP Libraries as well as at the Department of Forest Research and Survey (DFRS), the Institute of Forestry (IoF) and the International Centre for Integrated Mountain Development (ICIMOD). Additional information were also acquired through internet.

\section{Data analysis and interpretation}

The information obtained from the herb inventory was analyzed using the Statistical Package for Social Science (SPSS) Software version 19. The results were then presented in the form of tables, graphs and charts. The quantitative data was analyzed as follows:
A) Frequency $=\frac{\text { No. of plots where species occcurs } x 100}{\text { Total no. of plots }}$
B) Relative Frequency $=\frac{\text { Frequency of species } x 100}{\text { Sum of all frequency }}$
C) Density $=\frac{\text { No. of species in all plots } \mathrm{x} 10,000 \mathrm{~m}^{2}}{\text { Total no. of plots } \mathrm{x} \text { area of a plot }}$

D) Relative Density $=\frac{\text { No. of species in all plots x } 100}{\text { Total no. of individuals of all species }}$

E) Abundance $=\frac{\text { No. of species in all plots } \mathrm{x} 10,000 \mathrm{~m}^{2}}{\text { No. of plots in which a species occurs } \mathrm{x} \text { area of a plot }}$

F) Coverage $(\%)=\frac{\text { Area occupied by a species x } 100}{\text { Area of a sample plot }}$

G) Relative Coverage $(\%)=\frac{\text { Coverage of a species x } 100}{\text { Total coverage of all species }}$

H) Important Value Index (IVI)=Relative Frequency+Relative Density+Relative Coverage

I) Simson's (1949) Index (C) $=\sum\left(\mathrm{P}_{\mathrm{i}}\right)^{2}$ and

J) Simson's Index of Dominance (D) $=1-\sum\left(\mathrm{P}_{\mathrm{i}}\right)^{2}$,

Where, $\mathrm{P}_{\mathrm{i}}$ is the proportion of the important value of the $i^{\text {th }}$ species $\left(\mathrm{P}_{\mathrm{i}}=\mathrm{n}_{\mathrm{i}} / \mathrm{N}, \mathrm{n}_{\mathrm{i}}\right.$ being the IVI of the $\mathrm{i}^{\text {th }}$ species and $\mathrm{N}$ being the Important Value of all species)

The Simpson's Index values range from 0 to 1 . The closer the value of Simpson's Index to 0 , the more diverse the plot will be. A plot with only one species would have a Simpson's Index value of 1 . Trends are opposite to those found for ShannonWeaver values since Simpson's Index values decrease with increased diversity (Reich et al., 2001). In practice, the values below 0.5 indicate a relatively even community, while high values are indicative of communities dominated by one or a few species.

K) Shannon-Weaver (1949) Index $(H)=-\sum_{(i=1)}\left(p_{i}\right) x \ln \left(p_{i}\right)$,

Where, $\mathrm{H}=$ index of species diversity, and

$P_{i}=$ the proportion of the important value of $i^{\text {th }}$ species $\left(P_{i}=n_{i} / N, n_{i}\right.$ is the important value index of the $\mathrm{i}^{\text {th }}$ species and $\mathrm{N}$ is the important value of all species)

Due to its logarithmic nature, the ShannonWeaver Index is sensitive to uncommon plant species and less sensitive to very common species (Krebs, 1989). The Shannon-Weaver Index can, theoretically, range from zero (a community with only one species, which is technically just a "population") to infinity. In practice though, a value of 7 indicates an extremely rich community while values under 1 suggest a community with low diversity. Often, values above 1.7 are taken to indicate a relatively diverse community. The qualitative data was analyzed descriptively. 


\section{Results and discussion}

\section{Distribution of $D$. hatagirea}

A total of two scientifically identified herbs viz. Himalayan rhubarb (Rheum australe) and Nepal dock (Rumex nepalensis) were found in the project site with dominance of $D$. hatagirea (Table 1). The altitudinal range of habitat distribution of $D$. hatagirea in the study site was from 3,200 m to $3,600 \mathrm{~m}$ above sea level, which was similar to the study done by Ranapal (2009). The aspect of habitat distribution of $D$. hatagirea in the study site was South-West.

Mean height, collar diameter, number of leaves and age of $D$. hatagirea

The height, collar diameter and age of each $D$. hatagirea plant were measured in each plot in which a total of $69 \mathrm{D}$. hatagirea plants were found in 26 measured plots.

From the inventory, it was found out that the mean height of $D$. hatagirea was $91.08 \mathrm{~cm}$ which was greater than $41.97 \mathrm{~cm}$ found by Ranapal (2009) and $60 \mathrm{~cm}$ by Dutta (2007). Ranapal (2009) used three individual plants (tall, medium and short) to calculate the mean height of $D$. hatagirea. Similarly, the diameters (at $5 \mathrm{~cm}$ above the ground) of $D$. hatagirea plants were measured, and the mean diameter was calculated. The mean collar diameter at $5 \mathrm{~cm}$ above the ground was found to be 1.63 while the mean age was found to be of 2 years and the mean number of leaves was found to be 5 . The difference in height might be due to the methodology used as well as the age/topographic/soil/climate factors. The greater number of $D$. hatagirea was found in the Southwest aspect.

\section{Frequency of $D$. hatagirea and its associates}

The study shows $72 \%$ occurrence of $D$. hatagirea in the sample plots. However, Ranapal (2009) has indicated the occurrence of $D$. hatagirea in Paplekharka as $71 \%$. Similarly, Rheum australe was found to have an occurrence of $8 \%$ as compared to $65 \%$ found by Ranapal (2009). On the other hand, Rumex nepalensis had an occurrence of $20 \%$ (Fig. 4 ).

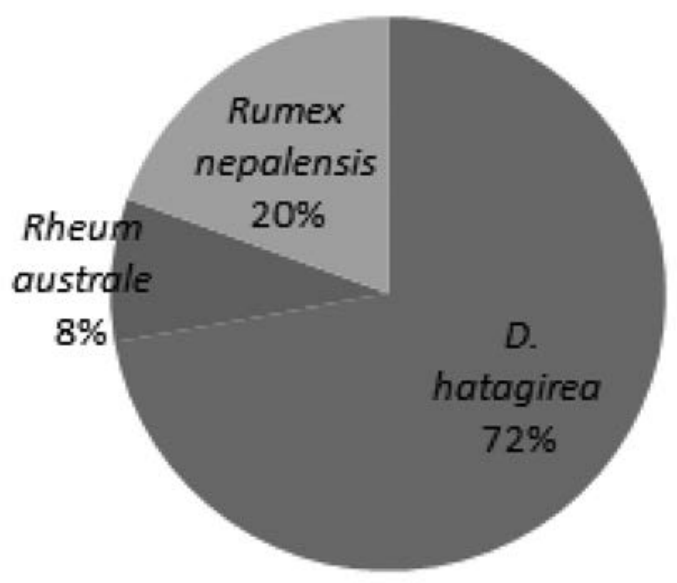

Fig. 4: Frequency of $D$. hatagirea and its associates Relative frequency of $D$. hatagirea and its
associates

Relative frequency is the frequency of a species in relation to other species. The relative frequency of $D$. hatagirea was high (69\%) as compared to its two associates. However, according to Ranapal (2009), it was $17 \%$. The species having the lowest frequency were Rumex nepalensis (22\%) and the Rheum australe $(9 \%)$.

\section{Density of $D$. hatagirea and its associates}

This study showed the highest density of 276 per ha of the Himalayan orchid (D. hatagirea) as compared to its associates (Table 2). This was comparatively far lower than the one $(1,671$ per ha) indicated by Ranapal (2009). The big difference might be due to the smaller area (4.5 ha) of the project site taken during the research period. The least number was that of Nepal dock with 80 per ha which might be due to the least

Table 1: List of identified herbs in the sample plots

\begin{tabular}{|c|c|c|c|c|c|}
\hline S.N. & Local name & English name & Scientific name & Family & Nature of plant \\
\hline 1. & Panchaunle & Himalayan Orchid & $\begin{array}{l}\text { Dactylorhiza hatagirea } \\
\text { (D. Don) Soo }\end{array}$ & Orchidaceae & Herb \\
\hline 2. & Padamchal & Himalayan Rhubarb & $\begin{array}{l}\text { Rheum australe D. } \\
\text { Don }\end{array}$ & Polygonaceae & Herb \\
\hline 3. & Halhale & Nepal Dock & $\begin{array}{l}\text { Rumex nepalensis } \\
\text { Spreng. }\end{array}$ & Polygonaceae & Herb \\
\hline
\end{tabular}


distribution of this species in the plot and heavy grazing pressure. The density of $D$. hatagirea was reported to be 0.2 individuals per $\mathrm{m}^{2}$ in Samar Lek of the Upper Mustang (Chhetri and Gupta, 2006). The next reported density of $D$. hatagirea

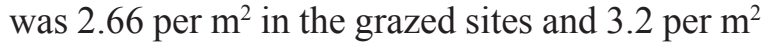
in the ungrazed sites at Tungnath, India (Nautiyal et al., 2004). The low density in the unprotected areas might be due to heavy grazing pressure.

Table 2: Density of $D$. hatagirea along with its associates

\begin{tabular}{llc}
\hline S.N. & Species & Density per ha \\
\hline 1. & D. hatagirea & 276 \\
2. & Rheum australe & 156 \\
3. & Rumex nepalensis & 80 \\
\hline
\end{tabular}

Relative density of $D$. hatagirea and its associates

Relative density is the density of a species with respect to the total density of all species (Ranapal, 2009). In the study site, D. hatagirea was found to have the highest relative density $(53.91 \%)$ as compared to those of its associates (Table 3). However, the study conducted by Ranapal (2009) indicated the relative density of $D$. hatagirea to be quite low, only $9 \%$ or 0.09 . The big difference in the relative density of this species might be because of the smaller area ( $4.5 \mathrm{ha}$ ) of the project site taken during the research period.

Table 3: Relative density of $D$. hatagirea along with its associates

\begin{tabular}{llc}
\hline S.N. & Species & Density per ha \\
\hline 1. & D. hatagirea & 53.91 \\
2. & Rheum australe & 30.47 \\
3. & Rumex nepalensis & 15.62 \\
\hline & Total & 100.00 \\
\hline
\end{tabular}

\section{Abundance of $D$. hatagirea and its associates}

Rumex nepalensis was found to have the highest abundance of 2,666.67 per ha followed by Rheum australe with 2,228.57 per ha with the Himalayan orchid having the least abundance of 1,061.54 per ha. However, the abundance of $D$. hatagirea as reported by Ranapal (2009) was higher (2,367 per ha) than the one found in this study; the difference might be due to the least number of Himalayan orchid plants found in the study area.
Coverage and relative coverage of $D$. hatagirea and its associates

D. hatagirea was found to have the highest coverage $(26 \%)$ and highest relative coverage $(72.2 \%)$ as compared to those of Rheum australe and Rumex nepalensis (Table 4). The highest coverage of $D$. hatagirea was due to the highest number of plots in which it occurred as compared to its associates.

Table 4: Coverage and relative coverage of $D$. hatagirea along with its associates

\begin{tabular}{llcr}
\hline S.N. & \multicolumn{1}{c}{ Species } & $\begin{array}{c}\text { Coverage } \\
\mathbf{( \% )}\end{array}$ & $\begin{array}{c}\text { Relative } \\
\text { Coverage (\%) }\end{array}$ \\
\hline 1. & D. hatagirea & 26.00 & 72.22 \\
2. & Rheum australe & 7.00 & 19.45 \\
3. & $\begin{array}{l}\text { Rumex } \\
\text { nepalensis }\end{array}$ & 3.00 & 8.33 \\
\hline & & \\
\hline
\end{tabular}

Important Value Index of $\boldsymbol{D}$. hatagirea and its associates

D. hatagirea was found to have the highest IVI (187.24) as compared to its two associates (Table $5)$, indicating its dominance in the study site.

Table 5: Important Value Index of $D$. hatagirea along with its associates

\begin{tabular}{llc}
\hline S.N. & Species & IVI \\
\hline 1. & D. hatagirea & 187.24 \\
2. & Rheum australe & 69.35 \\
3. & Rumex nepalensis & 32.29 \\
\hline & Total & 288.88 \\
\hline
\end{tabular}

Diversity indices for $D$. hatagirea and its associates

The Simson's Index (C) and the Simson's Index of Dominance (D) were found to be 0.41 and 0.59 , respectively (Table 6), indicating relatively even community and higher dominance of one species i.e. D. hatagirea in the study site. Similarly, the Shannon-Weaver Index $(\mathrm{H})$ was found to be 3.27, indicating relatively diverse community in the study site. The difference was due to the presence of the greater number of $D$. hatagirea individuals as compared to its two associates. The diversity of the species in the study site was, therefore, not satisfactory. 
Table 6: Simson's index of dominance and Shannon-Weaver Index for D. hatagirea and its associates

\begin{tabular}{|c|c|c|}
\hline Diversity Index & Value & Remarks \\
\hline $\begin{array}{l}\text { Simsons' Index } \\
\text { (C) }\end{array}$ & 0.41 & $\begin{array}{l}\text { Relatively even } \\
\text { community }\end{array}$ \\
\hline $\begin{array}{l}\text { Simsons' Index } \\
\text { of Dominance } \\
\text { (D) }\end{array}$ & 0.59 & $\begin{array}{l}\text { Higher dominance } \\
\text { of one species i.e. } \\
\text { D. hatagirea }\end{array}$ \\
\hline $\begin{array}{l}\text { Shanon-Weaver } \\
\text { Index }(\mathrm{H})\end{array}$ & 3.27 & $\begin{array}{l}\text { Relatively diverse } \\
\text { community }\end{array}$ \\
\hline
\end{tabular}

\section{Conclusion}

The study revealed that frequency, relative frequency, relative density, relative abundance and relative coverage of $D$. hatagirea were higher as compared to its two associates- Rhuem australe and Rumex nepalensis. This indicated the good ecological status of $D$. hatagirea in the study area. However, the value of Simson's Index (C) indicated the relatively even community and the Simson's Index of Dominance (D) indicated the dominance of one species i.e. D. hatagirea while the value of the Shannon-Weaver Index $(H)$ indicated relatively diverse community i.e. the plant diversity was found to be not satisfactory, suggesting for necessary actions for the conservation of the diversity of $D$. hatagirea in the study area. Further research is recommended on an annual basis so as to maintain database on the population dynamics and the harvesting level of this valuable medicinal plant. Research on genetic diversity using Molecular Marker Technique is also recommended to compare the genetic diversities of the populations of this orchid at different locations of Nepal. Although the occurrence of $D$. hatagirea was found to be higher than its two associates, the illegal harvesting of this valuable orchid and overgrazing in the study site are likely to bring it to extinction. Therefore, awareness programmes about the in-situ and exsitu conservation of the endangered medicinal orchid D. hatagirea should be conducted in the study area.

\section{Acknowledgements}

We are obliged to the Rufford Small Grants Foundation, United Kingdom for financial support to conduct the study. We are grateful to the research assistants, the community people of Ghasa and Annapurna Conservation Area Project for their necessary support, and Department of National Parks and Wildlife Conservation for allowing permission to conduct the research in the study area.

\section{References}

ACAP. 2009. Management Plan of Annapurna Conservation Area (2009-2012). Annapurna Conservation Area Project, Pokhara, Nepal.

Baral, S. R. and Kurmi, P. P. 2006. ACompendium of Medicinal Plants in Nepal. Kathmandu, Nepal.

Bhattarai, K. R. and Ghimire, M. D. 2006. Commercially important medicinal and aromatic plants of Nepal and their distribution pattern and conservation measure along the elevation gradient of the Himalayas. Banko Janakari 16 (1): 3-13.

CAMP. 1998. Executive Summary Report of the Conservation Assessment and Management Plan (CAMP) of the Biodiverity Conservation Prioritisation Project on Selected Medicinal Plants of Northern, North-eastern and Central India. [http://msubiology.info/vesna/nauka/ pillon2006.pdf accessed on 29 March, 2014.

Chaurasia, O. P., Ahmed, Z. and Ballabh, B. 2007. In Ethnobotany and Plants of TransHimalaya. Satish Serial Publishing House, Delhi, India.

Chhetri, H. B. and Gupta, V. N. P. 2006. NTFP potential of Upper Mustang, a TransHimalayan region in western Nepal. Scientific World 4 (4): 38-43.

Colwell, R. K. 2009. "Biodiversity: Concepts, Patterns and Measurement". In The Princeton Guide to Ecology (ed) Levin, S.A. Princeton University Press, Princeton, 257-263. http:// press.princeton.edu/chapters/s3_8879.pdf accessed on 23 August, 2014.

DPR. 2006. Prioritized Medicinal Plants for Economics Development of Nepal. Government of Nepal, Department of Plant Resources (DPR), Kathmandu, Nepal.

Dutta, I. C. 2007. Non-Timber Forest Products of Nepal: Identification, Classification, Ethnic Uses and Cultivation. Hill Side Press, Kathmandu, Nepal.

IUCN. 2004. National Register of Medicinal and Aromatic Plants. International Union 
for Nature Conservation Nepal, Kathmandu, Nepal.

Krebs, C. J. 1989. Ecological Methodology. Harper Collins College Publishers, New York, USA.

Nautiyal, M. C., Nautiyal, B. P. and Prakash, V. 2004. Effect of grazing and climatic changes on alpine vegetation of Tungnath, Garhwal Himalaya, India. The Environmentalist 24: 125-134.

Phoboo, S., Devkota, A. and Jha, P. K. 2008. Medicinal Plants in Nepal- An Overview. Medicinal Plants in Nepal, an anthology of contemporary research. Ecological Society, Kathmandu, Nepal.

Pillon, Y., Fay, M. F., D. S., Shipunov, A. and Chase, M. W. 2005. Species diversity versus phylogenetic diversity: a practical study in the taxonomically difficult genus Dactylorhiza (Orchidaceae). Biological Conservation 129: 4-13.

Ranapal, S. 2009. An Assessment of Status and Antibacterial Properties of Dactylorhiza hatagirea in Annapurna Conservation Area (A Case Study of Paplekharka, Lete VDC, Mustang). B.Sc. Forestry Research Thesis submitted to Tribhuvan University, Institute of Forestry, Pokhara, Nepal.

Ravindranath, S. and Premnath, S. 1997. Biomass Studies: Field Method for Monitoring Biomass. Oxford and IBH Publishing Co. Pvt. Ltd., India.
Reich, P. B., Bakken, P., Carlson, D., Frelich, L., Friedman, S. K. and Grigal, D. 2001. Influence of logging, fire and forest type on biodiversity and productivity in southern boreal forests. Ecology 82 (10): 2731-2748.

Samant, S. S., Dhar, U. and Rawal, R. S. 2001. Himalayan Medicinal Plants- Potential and Prospects (eds) Samant, S. S., Dhar, U. and Palni, L. M. S. Gyanodaya Prakashan, Nainital, India, 166-184.

Shanon, C. E. and Weaver, W. 1949. The Mathematical Theory of Communication. University of Ilinois Press, Urbana, Ilinois, USA.

Shrestha, G. L. and Shrestha, B. 1999. An Overview of Cultivated Plants in Nepal; Proceedings of National Conference, the Green Energy Mission/Nepal, Kathmandu, Nepal.

Simpson, E. H. 1949. Measurement of diversity. Nature 163: 68.

Srivastava, R. C. and Mainera, A. K., 1994. A note on Dactylorhiza hatagirea (D. Don) Soo: an important medicinal orchid of Sikkim. National Academy of Science Letters 17: 129-130.

Wollenberg, E. 1999. Methods for assessing the conservation and development of forest products. In Incomes from the Forest (ed) Wollenberg, E. and Ingles, A. CIFOR. Indonesia, 1-16. 